\title{
ANTI-MELANOMA BIO-EFFICACY OF THE PLANT MADHUCA LONGIFOLIA AND ITS ENHANCEMENT USING BIOACTIVE PRINCIPLE LOADED GOLD NANOPARTICLE
}

\author{
SAURABH YADAV ${ }^{1}$, MUKTI SHARMA ${ }^{1}$, NARAYANAN GANESH ${ }^{2}$, SHALINI SRIVASTAVA ${ }^{1}$, M. M. SRIVASTAVA ${ }^{1 *}$

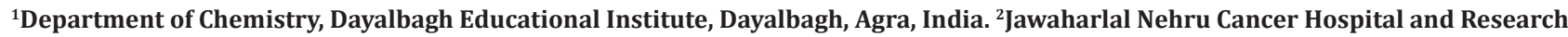 \\ Center, Bhopal, India. *Email: dei.smohanm@gmail.com
}

Received: 22 June 2020, Revised and Accepted: 14 August 2020

\section{ABSTRACT}

Objective: Unexplored in-vivo anti-melanoma bio-efficacy of the plant Madhuca longifolia (bark) has been carried out against C57BL/6 mice.

Methods: Optimized experimental conditions of phytofabrication of gold nanoparticles were as follows: flavonoid content $(1 \mathrm{ml}, 0.5 \mathrm{mg} / \mathrm{ml})$, sodium tetrachloroaurate dihydrate solution $(2 \mathrm{ml}, 1 \mathrm{mM})$, and sonication $(15 \mathrm{~min}, 20 \mathrm{KHz})$ at $\mathrm{pH}$ 4. The optical properties; ultraviolet-visible spectrophotometer (UV-Vis), particles size and zeta potential (Zetasizer), miller indices; X-ray diffraction (XRD), morphology; field emission-scanning electron microscope (FE-SEM), particle size; high resolution-transmission electron microscopy (HR-TEM), surface roughness; atomic force microscopy (AFM) and elemental composition; and energy dispersive X-rays (EDX) of flavonoid loaded gold nanoparticles. In-vivo anti-melanoma bio-efficacy has been carried out against C57BL mice. Radioisotopic, hematological, and histopathological studies were carried out using standard procedures.

Results: Redox potential of the total flavonoid extracted from the bark of the plant (Madhuca longifolia) has been used for the fabrication of flavonoid loaded gold nanoparticles (F@AuNp) and confirmed for the first time their significant anti-melanoma bio-efficacy. The finding is supported by hematological and histopathological studies carried out in the organs (liver, kidney, and intestine) of C57BL mice. The significant enhancement in phytofabricated F@AuNp compared to native bark extract of the plant has been assigned to enhanced stay period and nanosizing, biocompatibility, nontoxic nature, and enhanced beneficial payload to the cancerous cells.

Conclusion: Such phytofabricated gold nanoparticles possess an admirable prospect for the expansion of herbal nanomedicine for anti-melanoma bio-efficacy.

Keywords: Madhuca longifolia, Flavonoid, Gold nanoparticles, Enhanced bio-efficacy.

(c) 2020 The Authors. Published by Innovare Academic Sciences Pvt Ltd. This is an open access article under the CC BY license (http://creativecommons. org/licenses/by/4. 0/) DOI: http://dx.doi.org/10.22159/ajpcr.2020.v13i10.38832

\section{INTRODUCTION}

Recent realization that folk plants indicated for various bio-efficacies should be established scientifically and to make the use of their active template molecules in biomedical research. Plant secondary metabolites such as vinblastine, vincristine, etoposide, teniposide, taxanes, camptothecin, irinotecan, and topotecan have been well recognized as antioxidants and anticancer bio-agents for direct inhibition of cell proliferation [1-5]. The meagre in-vivo bioavailability of plant secondary metabolites [6] owing to their rapid and extensive metabolism has directed research efforts toward the enhanced accumulation of phyto-modalities in the tumor cells with no or minimum potential toxicity to healthy cells $[7,8]$. Plant-mediated fabrications of noble metal nanoparticles have signified themselves as an important tool for the enhancement in the pharmacological efficacies. Research devotion has been paid toward the use of diverse plant extracts as such or their bioactive constituents for the phytofabrication of metal nanoparticles [9-22].

Madhuca longifolia (Mahua) belongs to the Sapotaceae family and is an Indian tropical tree found in most part of the country like West Bengal, Maharashtra, Madhya Pradesh, Kerala, Gujarat, Orissa, Chhattisgarh, Jharkhand Uttarakhand, and Uttar Pradesh [23-25]. Among the tribe's society, its different parts are used as folk remedies for skin-related issues, wound healing, swelling, antioxidant, and local liquor formation [26-28]. Phytochemical screening of various parts of the plant Madhuca longifolia has been restricted mainly to qualitative analysis, exploring the presence of polyphenolics, flavonoids, terpenoids, saponins, tannins alkaloids, glycosides, and large series of plant acids [29]. Quantitative analyses using gas chromatography-mass spectrometry (GC-MS) and high-performance thin-layer chromatography (HPTLC) have shown the presence of a considerable amount of polyphenolics type compounds, confirming the presence of quercetin as flavonoid [30]. However, the presence of a pentacyclic triterpene derivative in a small amount has also been elucidated on the basis of extensive spectroscopic study [31]. The plant lacks detailed quantitative analysis. Madhuca longifolia is a folk plant of our current interest aiming for its nanoscale pharmacological perspectives.

In the perpetuation of our work on phytofabrication of noble nanoparticles for the enhancement of various bio-efficacies [32-37], we have recently explored in-vitro anti-melanoma bio-efficacy of the plant Madhuca longifolia (bark) against mice (B16F10) and human (A375) melanoma cell lines [35]. The present communication for the first time reports in-vivo anti-melanoma bio-efficacy of the plant Madhuca longifolia (bark) against C57BL/6 mice model. The witnessed anti-melanoma bio-efficacy has been successfully enhanced using gold nanoparticles loaded with flavonoids. The proposed flavonoid loaded gold nanoparticles are labeled as (F@AuNp) and used throughout the manuscript. Such medicinally benign active principle loaded gold nanoparticles possess an admirable panorama for the advancement of commendation of herbal Nano-medicine.

\section{METHODS}

Extraction and characterization of flavonoid

Microwave-assisted extraction of the plant (bark; $5 \mathrm{~g}$ ) was carried out in aqueous-alcoholic solution at $200 \mathrm{~W}$ for $5 \mathrm{~min}$ and was used for the quick test of the formation of gold nanoparticles. For a detailed study, cleaned, shade dried, and powdered bark $(200 \mathrm{~g})$ was defatted 
with petroleum ether $\left(60-80^{\circ} \mathrm{C}\right)$ for $24 \mathrm{~h}$. The defatted extract was subjected to the Soxhlet extraction with aqueous-ethanol for $72 \mathrm{~h}$. The extract was concentrated by rotavapor distillation and finally dried by purging nitrogen and stored (bark extract=15.78 g) in the dark at $\pm 4^{\circ} \mathrm{C}$. Column chromatographic separation of the fraction (10 g) was carried out (length $120 \mathrm{~cm}$; diameter $4 \mathrm{~cm}$; mesh size 60; stationary phase; silica gel [125 g]) and washed with $\mathrm{CH}_{3} \mathrm{OH}$ : $\mathrm{CHCl}_{3}$ (3:7). After the removal of the solvent, a brown mass was obtained. The brown mass was re-chromatographed using column (length $150 \mathrm{~cm}$; diameter $3 \mathrm{~cm}$; stationary phase; silica gel [80 g]) and eluted [35] with solvent mixture $\mathrm{CHCl}_{3}: \mathrm{MeOH}$ (8:1). The brown mass portion was subjected to high-performance liquid chromatography-electrospray ionizationquadrupole time-of-flight-mass spectrometer (HPLC-ESI-QTOF-MS) for the characterization of the flavonoid compounds. HPLC-ESI-QTOF-MS analysis was performed on a quadrupole time-of-flight (QTOF) mass spectrometer connected with Agilent 1200-HPLC system through dual electrospray ionization interface (Agilent Technologies, USA). HPLC separation was carried out on a Poroshell 120 EC-C18 column (50 $\mathrm{mm} \times 4.6 \mathrm{~mm}, 2.7 \mu$ ). The mobile phase consisted of $0.1 \%$ formic acid solution (A) and methanol (B) with a flow rate of $0.5 \mathrm{ml} / \mathrm{min}$ under the gradient program of $30-90 \%$ (B) for the initial $10 \mathrm{~min}$, then $90 \%$ (B) from 10 to $20 \mathrm{~min}, 90$ to $30 \%$ (B) from 20 to $25 \mathrm{~min}$, and $30 \%$ (B) from 25 to $30 \mathrm{~min}$. The HPLC-ESI-QTOF-MS was carried out in positive ESI mode. The resolving power of the QTOF analyzer was set above 10,000 (FWHM). The spectra were acquired within a mass range of $\mathrm{m} / \mathrm{z}$ 100-1500. The capillary temperature was set to $350^{\circ} \mathrm{C}, \mathrm{N}_{2}$ nebulizer pressure (40 psi), and gas flow rate $(10 \mathrm{l} / \mathrm{min})$.

\section{Fabrication and Characterization of F@AuNp}

Optimized experimental conditions of phytofabrication of gold nanoparticles were as follows: Total flavonoid content $(1.0 \mathrm{ml} ; 0.5 \mathrm{mg} / \mathrm{ml})$, sodium tetrachloroaurate dihydrate solution $(2 \mathrm{ml}$; $1 \mathrm{mM}$ ), and sonication (15 min; $20 \mathrm{KHz}$ ) at pH 4. The optical properties (UV-Vis spectrophotometer, Lab India, India), miller indices (XRD, Bruker AXS D8 Advance, Germany), surface morphology (FE-SEM, Nova Nano FE-SEM 450, Netherland), surface roughness (AFM, Nanosurf Easyscan V 1.8, Switzerland), particles size (HR-TEM, Tecnai G2 T 20 ST, Germany) zeta size, zeta potential (Zetasizer, Nano ZS90 model Malvern, Germany), and elemental composition (EDX, Tecnai G2 T 20 ST, Germany) of F@AuNp were measured.

\section{In-vivo anti-melanoma activity}

\section{Cell culture}

The mice melanoma (B16F10) cell line was obtained from NCCS, Pune, India, and grown in Dulbecco's Modified Eagle's Medium containing antibiotics, L-glutamine (2 $\mathrm{mM}$ ), and fetal bovine serum (FBS; 10\%). Cells were kept at $37 \pm 0.2^{\circ} \mathrm{C}$, with relative humidity (100\%), $\mathrm{CO}_{2}(5 \%)$, and air (95\%). The culture medium was changed thrice in a week. The single-cell suspension was made using trypsin-ethylene di-amine tetra acetic acid. The cell suspension was diluted with media containing FBS (5\%) to obtain final density $\left(2 \times 10^{5}\right.$ cells $\left./ \mathrm{ml}\right)$.

\section{Animal experiments}

Random breed, 5-6 weeks old, and 24-28 g body weight (bw) bearing C57BL healthy mice were maintained under controlled standard environmental conditions of the temperature at $25 \pm 1^{\circ} \mathrm{C}$ with relative humidity (55-65\%) under dark and light cycle (14 h:10 h). The animals were fed with standard pellet diet and tap water ad libitum.

\section{Ethics statement}

The Guidelines of the Committee (CPCSEA) was followed for all the animal experiments against ethical permission No. 1698/P0/a/13/ CPCSEA, Govt. of India.

\section{Experimental designing}

Acute oral toxicity test was performed as per the Organization for Economic Co-operation and Development (OECD) guideline 423 (OECD, 2010 ) on C57BL/6 mice. The animals were randomly divided into six groups of six animals each. Cells $\left(2 \times 10^{5} / \mathrm{ml}\right)$ in phosphate buffer saline and suspension $(200 \mu \mathrm{l})$ were maintained and subcutaneously injected into mice on the dorsal side. After the $4^{\text {th }}$ day of injection, the tumor started budding. At the palpable stage of the tumor, the treatments at $(\mathrm{mg} / \mathrm{kg}, \mathrm{bw})$ of mice were given orally. Cyclophosphamide (reference drug; $150 \mathrm{mg} / \mathrm{kg}$ ) was intraperitoneally injected every day for 21 days. During the treatment, the size of the implanted tumor was measured at regular time intervals. Group, I served as normal control (NC). The remaining animals were inoculated with B16F10 (cells/mice) and further divided into five groups. Group II served as tumor control (TC), while Group III served as a positive control (PC) and treated with the reference drug (cyclophosphamide; $150 \mathrm{mg} / \mathrm{kg}$; bw). Group IV (BE) was treated with aqueous ethanolic bark extract (500 mg/kg; bw). Group V (FC) was treated with flavonoid content (250 mg/kg; bw). Group VI was treated with F@AuNp (150 mg/kg; bw). All the treatments were given orally after $24 \mathrm{~h}$ of inoculation and continued for $21^{\text {st }}$ days (once daily). After the last dose, all mice from each group were sacrificed. All the treatments were administered orally through a metal oropharyngeal cannula while the reference drug was given intraperitoneally. Cyclophosphamide, an anti-neoplastic drug frequently used in treating malignancies; therefore, it was used in the present study.

To observe any life-threatening toxicity of the samples and reference drug, body weights of all animals were measured daily during the treatment period. Tumor growth was determined by measuring the diameter using digital Vernier Caliper daily from the very $1^{\text {st }}$ day of the treatment. Tumor volume (in $\mathrm{mm}^{3}$ ) was calculated [38]. Tumor growth delay was determined by the standard formula: T-C, where T represents median time (in days) required for the tumor's to reach a volume of $100 \mathrm{~mm}^{3}$ and $\mathrm{C}$ represents median time (in days) required for the control group to reach the same size [39].

\section{Hematological parameters}

The measurement of haematological parameters [haemoglobin, red blood cells, white blood cells, neutrophils, lymphocytes, and platelets counts] were carried out on the first day in blood sample $(0.3 \mathrm{ml})$ taken from retro-orbital plexus in ethylenediaminetetraacetic acid (EDTA) tube. After $24 \mathrm{~h}$ of the tumors cell's inoculation, the animals were given as per designed group treatments (once daily for the next 20 days). On the $21^{\text {st }}$ day, animals were sacrificed and the assessments of haematological parameters were again conducted.

\section{Radioisotopic study}

All the treatments were tagged with radiolabelled $\mathrm{Tc}^{99}$ using stannous chloride reduction [40]. The stannous chloride $\left(\mathrm{SnCl}_{2} \cdot 2 \mathrm{H}_{2} \mathrm{O}\right)(1 \mathrm{mg} / \mathrm{ml}$; $0.1 \mathrm{~N} \mathrm{HCl})$ and $\mathrm{F} @ A u N p$ were mixed in a vial containing $(100 \mu \mathrm{Ci} ; 3.7$ $\mathrm{MBq}^{99} \mathrm{TcO}^{4-}$ ) procured from the Department of Nuclear Medicine, Jawaharlal Nehru Cancer Hospital and Research Center, Bhopal, India. The reaction mixture was vortexed and kept at ambient temperature. All the treatments tagged with $\mathrm{Tc}^{99}$ were administered in mice through the tail vein and scanned using the Brivo NM 615 scanner at different time intervals.

\section{Histopathological studies}

The body organs (liver, kidneys, and intestine) were removed and processed overnight for dehydration, cleaning, impregnation in an automatic tissue processor (Sakura, Japan) and fixed in $10 \%$ the solution of neutral buffered formalin. The organs were embedded in paraffin blocks followed by sectioning (sections of $5 \mu \mathrm{m}$ ) and staining with hematoxylin and eosin. Slides were examined under a light microscope. The alterations compared to the normal structure were registered. The tumors from each group were dissected and subjected to the abovementioned treatment course and stained using hematoxylin and eosin. The architecture of the sections was examined using a microscope [41].

\section{Statistical analysis}

One-way ANOVA (Tukey-Kramer) was used for statistical analysis and results were given as mean $\pm \mathrm{SD}$. The significance of the value was considered at $\mathrm{p}<0.05$ and $\mathrm{p}<0.01$. 


\section{RESULTS AND DISCUSSION}

Among the plant secondary metabolites, flavonoids are a broad class of polyphenolics biomolecules with numerous hydroxyl groups and are capable to interact with cell membranes and penetrate more or less deep into hydrophobic cellular sites. They have high medicinal potential behaving as strong antioxidants. Antioxidants, as immunity boosters, have also been proved to strengthen the anticancer activity [42-44]. Relevant literature indicates the presence of flavonoid in a substantial amount in the plant Madhuca longifolia. The total phenolics and flavonoids content in aqueous ethanolic extract of the bark was experimentally measured and found in quite a substantial amount $(35.94 \pm 0.15 \mathrm{mg} / \mathrm{g})$ and $(12.15 \pm 0.15 \mathrm{mg} / \mathrm{g})$, respectively. The fact has motivated us to quantify the presence of total polyphenolics and flavonoids in the target plant and to study their role toward in-vivo anti-melanoma bio-efficacy.

The detailed LC-MS characterization of flavonoids extracted from the plant (bark), fabrication of gold nanoparticles loaded with total flavonoid content, and their characterization have been published in our earlier publication [35] in which we have also demonstrated noncytotoxicity of bark extract and flavonoid loaded gold nanoparticles (F@AuNp) toward the normal lymphocytes cells at the doses selected for the in-vitro assessment of anti-melanoma bio-efficacy. However, the relevant information has been summarized as follows. HPLC-ESI-QTOF chromatogram (Fig. 1) ascertained the presence of seven flavonoids: 3, 6 dihydroxyflavone; $\mathrm{m} / \mathrm{z} 255.06$; retention time 13.9 min (15), dihydroquercetin; $\mathrm{m} / \mathrm{z} 301.21$; retention time $23.6 \mathrm{~min}$ (23), quercetin; $\mathrm{m} / \mathrm{z} 303.05$; retention time $10.1 \mathrm{~min}$ (11), myricetin; $\mathrm{m} / \mathrm{z}$ 319.04; retention time $7.6 \mathrm{~min}$ (8), myricetin 3-0-arabinoside; $\mathrm{m} / \mathrm{z}$ 451.08; retention time $4.9 \mathrm{~min}$ (6), myricetin 3-0-galactoside; $\mathrm{m} / \mathrm{z}$ 481.09; retention time $4.8 \mathrm{~min}(5)$, and dihexosylquercetin; $\mathrm{m} / \mathrm{z}$ 621.31; retention time 23.6 min (32) along with other peaks of fatty acids.

The strong synergistic reduction potential of a family of flavonoids extracted from the bark of the plant $M$. longifolia was used for the phytofabrication of F@AuNp. Table 1 presents the complete characterization of phytofabricated F@AuNp at a glance.

\section{Enhancement of stay period}

To monitor the stay period of extracted flavonoid and its loaded gold nanoparticles, radiolabelling experiments were conducted using $\mathrm{Tc}^{99}$ as a radioactive tracer having photon emission energy $(140 \mathrm{KeV})$ and half-life (6.0058 h). Radioisotopic scintigraphic images of the melanoma tumors exhibit 4 and 6-h stay periods of flavonoid content and radiolabelled F@AuNp, respectively (Fig. 2). After 4 h, native flavonoid content starts dissipating from the target site. The short-stay period of native phytoextract has also been noticed earlier $[44,45]$. The present study demonstrates an improved stay period of gold nanoparticles loaded with plant flavonoids, finally leading to improved bio-availability.

\section{In-vivo anti-melanoma activity}

Noncytotoxic potential of phytotreatments against human lymphocytes cells

The mean body and tumor weights, tumor volume, and delay in tumor growth (21 ${ }^{\text {st }}$ days) in C57BL/6, mice model of all the experimental group's negative control (NC), tumor control (TC), bark extract (BE), flavonoids content (FC), flavonoids loaded gold nanoparticles (F@ AuNp), and positive control (PC) have been tabulated (Table 2). All the experimental groups were also periodically monitored for any non-specific toxicity such as food and water withdrawal with impaired movement.

A perusal of Table 2 depicts the following orders of target parameters among all the experimental groups: Mean tumor weight: $P C<F @ A u N p$ $<F C<B E<T C$, Mean tumor volume: $T C>B E>F C>F @ A u N p>P C$, and Mean tumor delay time: $P C>F @ A u N p>F C>B E>T C$. The delay time and tumor volume in $F @ A u N p$ treated the group almost matches with that of the reference drug, justifying the promising anti-melanoma efficacy of proposed phytofabricated F@AuNp histopathological observations of various target organs (Fig. 3-5) have been precisely depicted as follows.

\section{Intestine}

Group I (NC): Microscopic examination of the T.S. sections of intestine depicts the normal shape of intestinal layers, and crypt \& villi. Group II (TC): Broken serosa and muscularis layers, the appearance of fragmented villi in the coelomic cavity. Group III (PC):

Table 1: Salient features of the characterizations of F@AuNp

\begin{tabular}{|c|c|c|}
\hline Techniques & Observations & Findings \\
\hline UV-Vis & $\lambda_{\max }=536 \mathrm{~nm}$ & $\begin{array}{l}\text { Formation of desired } \\
\text { nanoparticles (F@AuNp) }\end{array}$ \\
\hline XRD & $\begin{array}{l}\text { Diffraction peaks }(2 \theta) \text { at } \\
38.2^{\circ}, 44.5^{\circ} \text {, and } 64.7^{\circ} \text {. }\end{array}$ & $\begin{array}{l}\text { Indexed to (111), (200), } \\
\text { and ( } 220) \text { lattice face- } \\
\text { centered cubic. }\end{array}$ \\
\hline FE-SEM & $\begin{array}{l}\text { Cubic, triangular, and } \\
\text { rectangular morphology. }\end{array}$ & Polydispersed layer. \\
\hline HR-TEM & Particles diameter & $\begin{array}{l}\text { Particle size range } 12.20 \text { - } \\
30.28 \mathrm{~nm} \text {. }\end{array}$ \\
\hline AFM & Surface roughness & $\begin{array}{l}\text { Average roughness of } \\
14.18 \mathrm{~nm} .\end{array}$ \\
\hline $\begin{array}{l}\text { DLS (Zeta } \\
\text { potential) }\end{array}$ & Negative charge & Zeta potential $(-31.6) \mathrm{mV}$. \\
\hline $\begin{array}{l}\text { DLS }\} \\
\text { (Zeta size) }\end{array}$ & Range (11.23 to $159 \mathrm{~nm}$ ) & $\begin{array}{l}\text { Z-average } 39.76 \mathrm{~nm} \text { and } \\
\text { PDI }(0.238)\end{array}$ \\
\hline EDX & $\begin{array}{l}\text { Peaks of Au at 0.34, 2.30, } \\
\text { and } 9.56 \mathrm{KeV}\end{array}$ & $\begin{array}{l}\text { Formation of F@AuNp } \\
\text { along with other elements } \\
\text { such as } \mathrm{C}, \mathrm{O}, \mathrm{N} \text { and } \mathrm{Cu}\end{array}$ \\
\hline
\end{tabular}

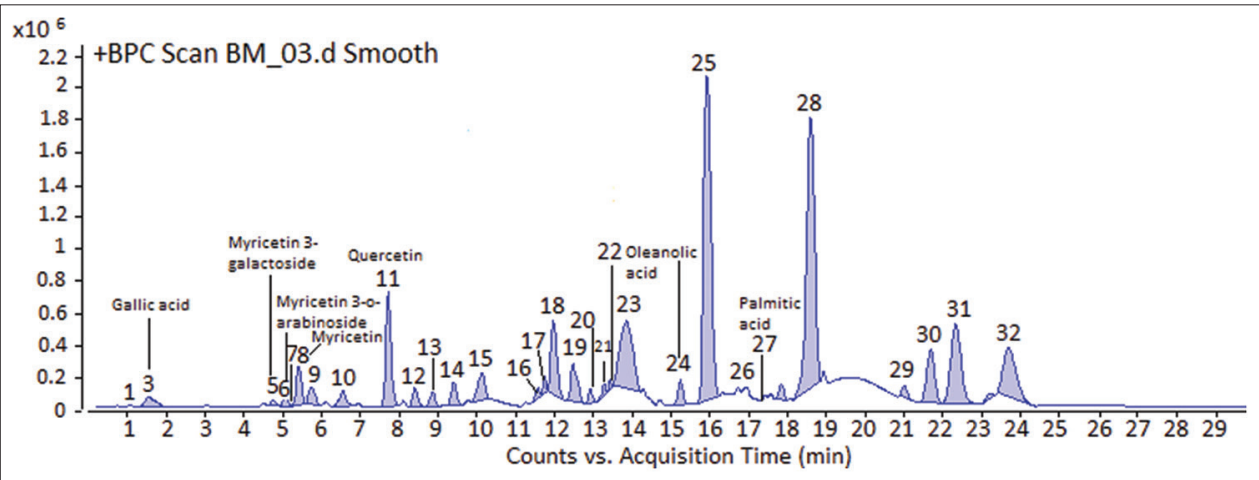

Fig. 1: HPLC-ESI-QTOF-MS chromatogram depicting the presence of flavonoids 
Table 2: Effect of mean body weight (BW), tumor weight (TW), tumor volume (TV), and tumor delay time (TDT) in various experimental groups

\begin{tabular}{|c|c|c|c|c|c|c|}
\hline Groups & Group I (NC) & Group II (TC) & Group III (BE) & Group IV (FC) & Group V (F@AuNp) & Group VI (PC) \\
\hline \multicolumn{7}{|l|}{ Parameters } \\
\hline BW (g) & $-27.25 \pm 1.87$ & $31.55 \pm 1.17$ & $30.31 \pm 1.15$ & $28.28 \pm 1.07$ & $26.12 \pm 1.02$ & $23.83 \pm 1.21$ \\
\hline TW (g) & - & $6.12 \pm 1.06$ & $4.97 \pm 1.34$ & $4.12 \pm 1.23$ & $3.75 \pm 1.38$ & $3.35 \pm 0.19$ \\
\hline $\mathrm{TV}\left(\mathrm{mm}^{3}\right)$ & - & $118.89 \pm 2.56$ & $38.70 \pm 1.89$ & $27.99 \pm 1.74$ & $24.92 \pm 1.55$ & $20.33 \pm 1.12$ \\
\hline TDT (days) & - & 0 & 1 & 3 & 5 & 6 \\
\hline
\end{tabular}

Each value is mean $\pm \operatorname{SD}(n=6)$, significance at $(\mathrm{p}<0.05)$

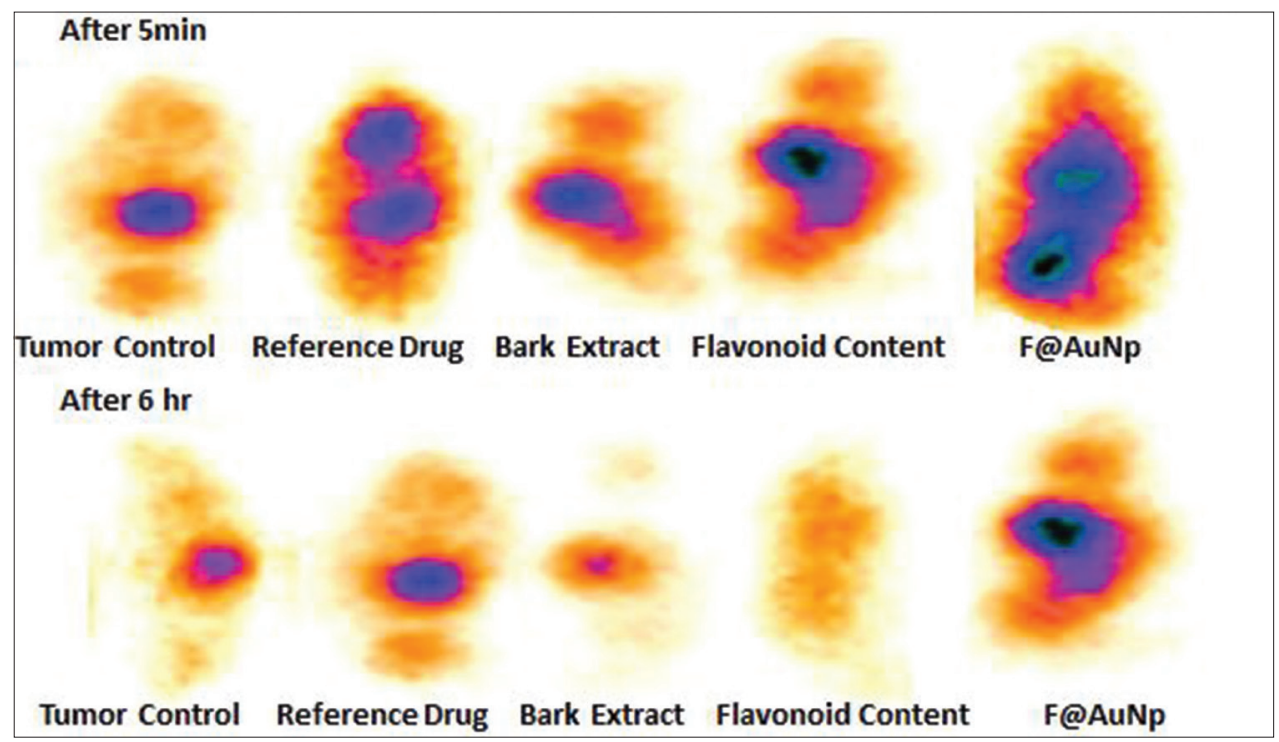

Fig. 2: Scintigraphic images of tumor-bearing animal of all the experimental groups tagged with Tc99

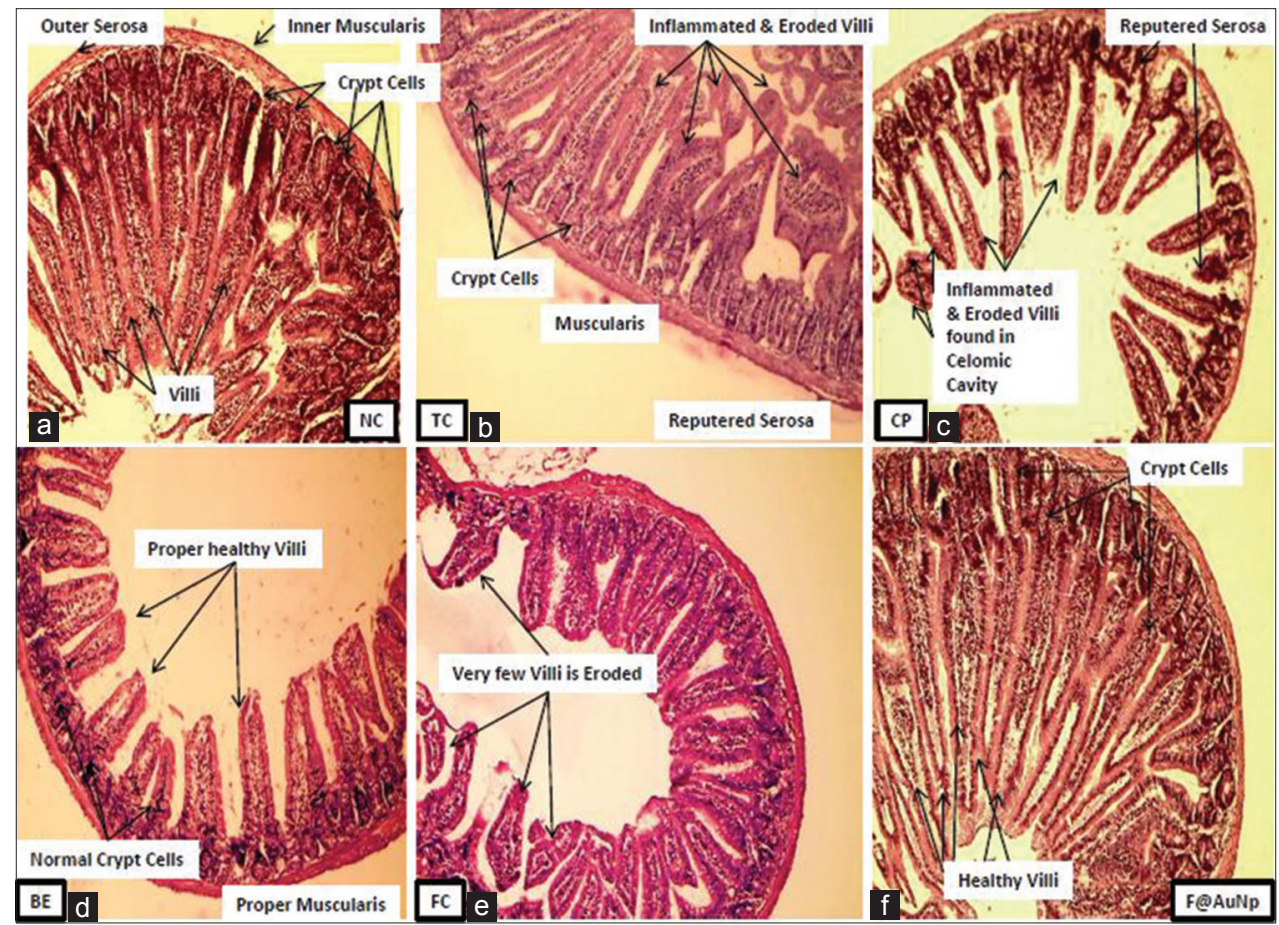

Fig. 3: T.S. of intestine of all experimental groups (a) NC, (b) TC, (c) PC, (d) BE, (e) FC, and (f) F@AuNp

Intestine architectural damage ruptured serosa and muscularis layer, inflammation, and fragmented villi in the coelomic cavity. Group IV (BE): Normal shape of intestinal layers, and crypt \& villi. Group V (FC):
Normochromic cells, intact serosa and muscularis, with inflammation in crypt and villi. Group VI (F@AuNp): A large number of healthy crypt and villi, proper shape of serosa, and muscularis layers. 


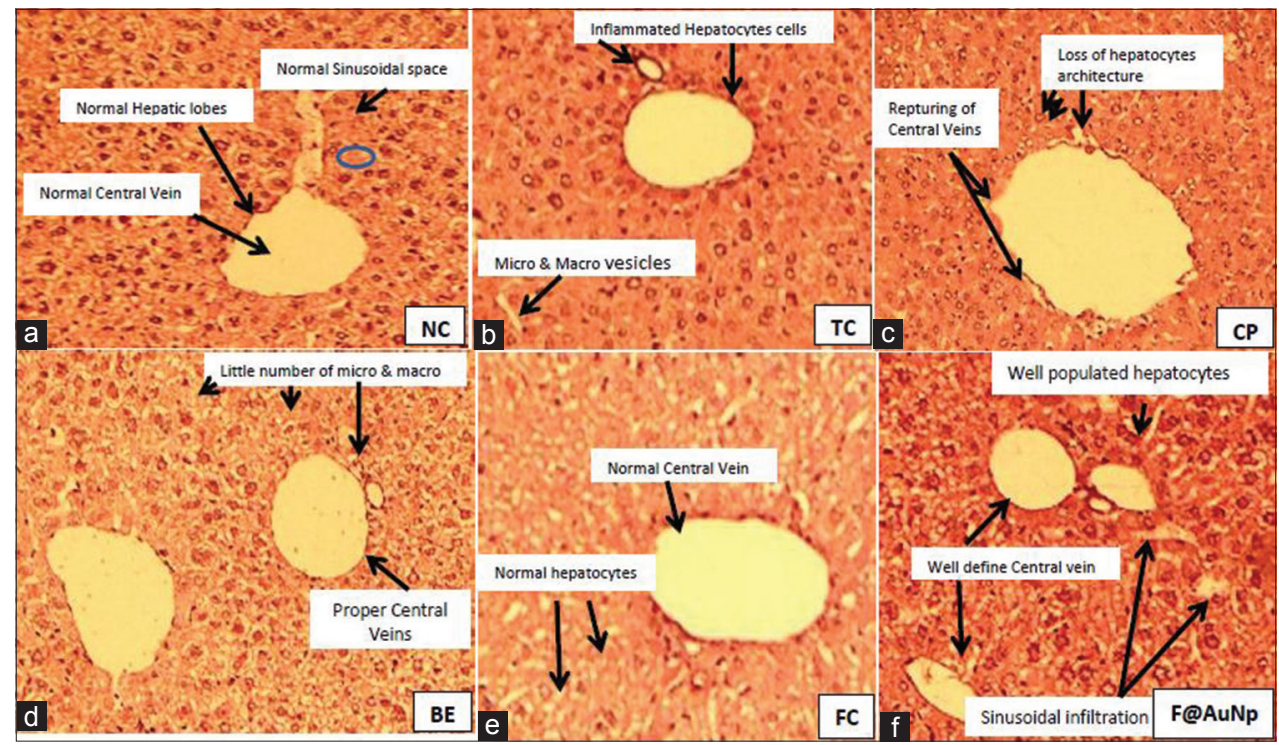

Fig. 4: T.S. of liver of all experimental groups (a) NC, (b) TC, (c) PC, (d) BE, (e) FC, and (f) F@AuNp

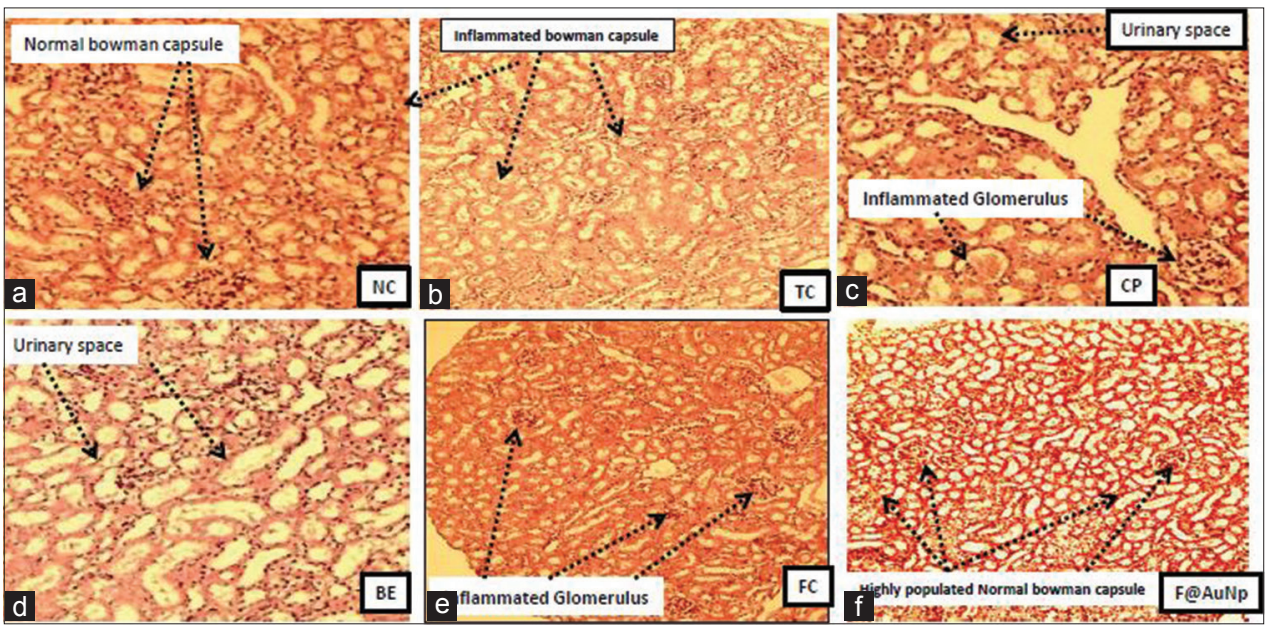

Fig. 5: T.S. of kidney of all experimental groups (a) NC,(b) TC, (c) PC, (d) BE, (e) FC, and (f) F@AuNp

\section{Liver}

Group 1 (NC): Normal hepatic lobes, cords of hepatocytes with normal sinusoids space, and normal central vein. Group II (TC): Appearance of few inflammatory cells with abundant micro and macro vesicles, loss of the radiating hepatocytes. Group III (PC): Fatty infiltration and central venous congestion (CVC) pronounced and loss of architecture of hepatocytes. Group IV (BE): Appearance of few inflamed cells with a little number of micro and macro vesicles. Group V (FC): Normal hepatocytes and central vein. Group VI (F@AuNp): Hexagonal hepatocytes with activation of Kupffer cells and slight sinusoidal infiltration.

\section{Kidney}

Group I (NC): Normochromic renal cells, with normal medullary rays, and renal glomeruli, the flat epithelium lining with the glomerular capsule. Group II (TC): Inflamed bowman capsules with widely spaced medullary rays and hypochromic renal cells. Group III (PC): Enlarge vascular glomeruli tightly filled with Bowman's capsule and appearance of widely spaced medullary rays with inflamed renal cells. Group IV (BE): Normal arrangement of renal glomeruli with flat epithelium lining and appearance of normal glomerular capsule. Group V (FC): Well-populated bowman capsule equally placed medullary rays. Group VI (F@AuNp): Normal renal parenchyma and glomerular with equally placed medullary rays.
It is inferred that there are no marked changes in the normal architectures (NC) of the target organ treated with F@AuNp. However, the reference drug (cyclophosphamide) treated group (PC) demonstrates noticeable damage to the normal architecture of body organs, warning the specific toxic nature of the reference drug. Other chemotherapeutic anticancer agents have also been reported to induce specific toxicity $[46,47]$. The C57BL/6 mice tumors of all the experimental groups were also subjected to histopathological studies (Fig. 6). Group II (TC): The presence of melanocytic tumor cells, hyper-vascularization with hyperchromic tumor cells. Group III (PC): Presence of few live tumor cells with a high density of necrosis and dysplastic cells. Group IV (BE): Presence of live tumor cells with apoptosis. Group V (FC): A larger number of apoptotic cells. Group VI (F@AuNp): Enhanced number of apoptotic cells with necrosis and inhibition in angiogenesis and micro-vessels.

The above observations demonstrate that among all the phytotreatments, there is a progressive increase in the anti-melanoma bio-efficacy in terms of apoptosis and necrosis, progressing from $\mathrm{BE}$ to $\mathrm{FC}$ and reaching to the optimum level in F@AuNp. The significant inhibition in angiogenesis and micro-vessels in F@AuNp treatment is the sign of its accumulation in tumor cells. The suppressed angiogenic vascularization has been reported to lead inhibition of tumor cell proliferation and apoptosis [48,49]. Finally, observations on hematological parameters of all the experimental groups of C57BL/6 mice also provide support to the 
prominent anti-melanoma bio-efficacy of phytofabricated F@ AuNp. The changes in hematological parameters induced by all the experimental groups have been summarized (Table 3 ).

The observed increase in WBC count in phytotreatments is a sign of development of a defense mechanism against malignancy which is in the divergence of the antitumor effect of a chemotherapeutic agent exhibiting a decrease in the WBC count [50]. All the phytotreatments again appear to reduce $\mathrm{HB}$ and $\mathrm{RBC}$ to a lesser extent compared to the reference drug. The development of anemia, an issue with most of the cancer chemotherapeutics and is faced as chemotherapeutic agentinduced myelosuppression activity [51]. The perceived increase in neutrophils and platelet counts and a decrease in lymphocytes in all the tumor-bearing animals relate with the promotion the proliferation of cancerous cells [52]. Thus, biocompatibility, tunable optical and electronic properties, and capping of medicinally important secondary metabolites (flavonoid) designate proposed nanoparticles (F@ AuNp) a suitable phytoagent to be developed for an upcoming drug

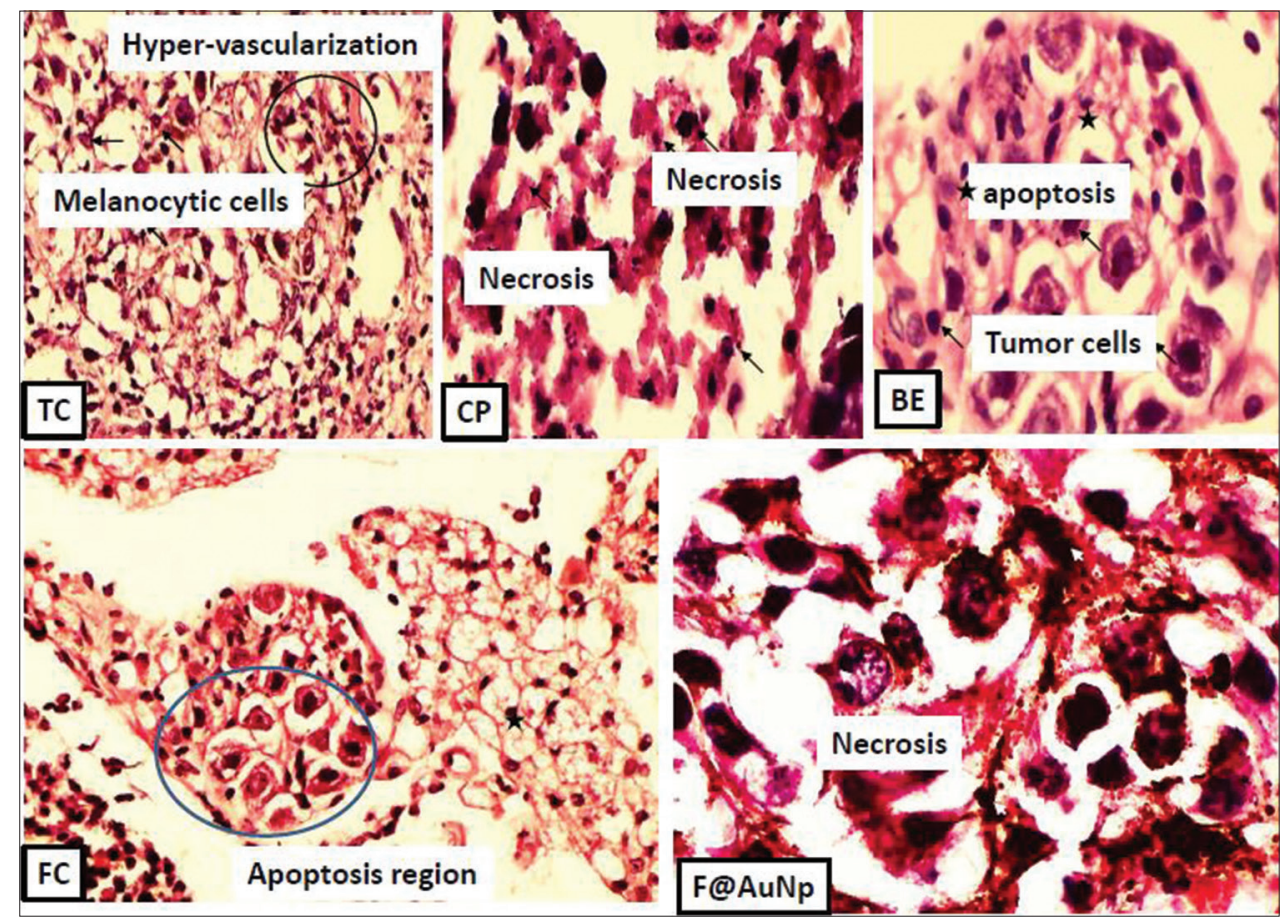

Fig. 6: Histopathological changes in tumors of all the experimental groups

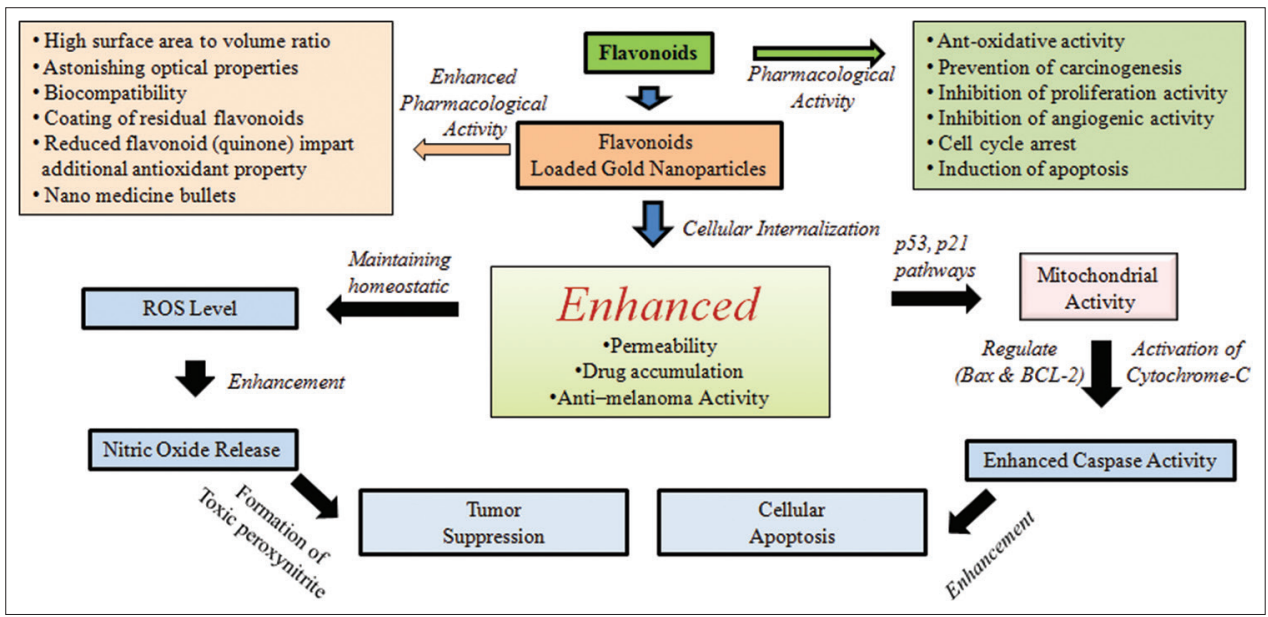

Scheme 1: Plausible mechanism for anti-melanoma activity of F@AuNp

Table 3: Effect of treatments on the hematological parameters of melanoma tumor-bearing mice

\begin{tabular}{|c|c|c|c|c|c|c|}
\hline Groups & $\mathrm{Hb}(\mathrm{g} / \mathrm{dl})$ & $\operatorname{RBC}\left(1 \times 10^{6} / \mu \mathrm{l}\right)$ & WBC $\left(1 \times 10^{3} / \mu \mathrm{l}\right)$ & Neutrophils (\%) & Platelets $\left(1 \times 10^{3} / \mu \mathrm{l}\right)$ & Lymphocytes (\%) \\
\hline $\mathrm{NC}$ & $14.0 \pm 0.24$ & $9.27 \pm 0.25$ & $6.20 \pm 0.47$ & $13.4 \pm 1.42$ & $683.2 \pm 32.14$ & $88.4 \pm 1.14$ \\
\hline $\mathrm{TC}$ & $9.4 \pm 1.43$ & $6.36 \pm 1.05$ & $75.73 \pm 23.14$ & $83.4 \pm 3.42$ & $1128.0 \pm 77.30^{* *}$ & $13.5 \pm 3.54^{* *}$ \\
\hline $\mathrm{BE}$ & $8.1 \pm 0.10^{*}$ & $5.43 \pm 0.74^{* *}$ & $35.01 \pm 4.32^{* *}$ & $63.5 \pm 3.21^{* *}$ & $964.0 \pm 72.25$ & $31.4 \pm 2.54$ \\
\hline FC & $8.4 \pm 0.10^{*}$ & $5.89 \pm 0.73^{*}$ & $38.61 \pm 4.02 *$ & $58.5 \pm 3.21^{*}$ & $954.0 \pm 75.25^{*}$ & $26.4 \pm 2.54 *$ \\
\hline F@AuNp & $9.8 \pm 0.18^{*}$ & $7.43 \pm 0.74$ & $13.21 \pm 2.21$ & $43.5 \pm 2.21 *$ & $854.0 \pm 20.25$ & $21.4 \pm 2.14^{*}$ \\
\hline $\mathrm{PC}$ & $8.7 \pm 1.25^{*}$ & $5.06 \pm 0.72^{* *}$ & $56.72 \pm 12.21^{* *}$ & $37.4 \pm 2.11^{* *}$ & $795.2 \pm 48.32$ & $10.6 \pm 1.84^{* *}$ \\
\hline
\end{tabular}

Each value is mean $\pm \mathrm{SD}(\mathrm{n}=6),{ }^{*} \mathrm{p}<0.05,{ }^{* *} \mathrm{p}<0.01$ significant, compared to control 
Table 4: Anti-melanoma bio-efficacy of M. longifolia: Position among various plants explored

\begin{tabular}{|c|c|c|c|c|}
\hline Plant Name & Plant Part & Dose & $\%$ inhibition & References \\
\hline $\begin{array}{l}\text { Copaifera } \\
\text { multijuga }\end{array}$ & Seed oil & $75 \mu \mathrm{g} / \mathrm{ml}$ & 47.12 & Lima et al., 2003 [53] \\
\hline $\begin{array}{l}\text { Crataegus } \\
\text { azarolus }\end{array}$ & Leaves & $400 \mu \mathrm{g} / \mathrm{ml}$ & 77.57 & Mustapha et al., 2015 [54] \\
\hline $\begin{array}{l}\text { Andrographis } \\
\text { nallamalayana }\end{array}$ & Leaves & $100 \mu \mathrm{g} / \mathrm{ml}$ & 80 & Purushotham et al., 2016 [55] \\
\hline $\begin{array}{l}\text { Hymenaea } \\
\text { courbali }\end{array}$ & Seed & $50 \mu \mathrm{g} / \mathrm{ml}$ & 58 & Spera et al., 2019 [56] \\
\hline $\begin{array}{l}\text { Sorbus } \\
\text { commixta }\end{array}$ & Fruit & $100 \mu \mathrm{g} / \mathrm{ml}$ & 83.47 & Jin et al., 2020 [57] \\
\hline $\begin{array}{l}\text { Madhuca } \\
\text { longifolia }\end{array}$ & Bark & $50 \mu \mathrm{g} / \mathrm{ml}$ & 65 & Yadav et al., 2019 [35] \\
\hline$F @ A u N p$ & Bark Extracted Flavonoid & $15 \mu \mathrm{g} / \mathrm{ml}$ & 85.15 & Yadav et al., 2019 [35] \\
\hline
\end{tabular}

delivery system. Nanosizing, inert character, and capability to attach with multiple surface components permit such plant composite nanoparticles to go through inside the cells and transport their payloads without eliciting an important immune reaction and any specific toxicity.

The exact mechanism of anti-melanoma action and its enhancement through F@AuNp has not been fully elucidated. Based on our experimental findings and pertinent information available, a tentative mechanism has been proposed in a précised schematic fashion (Scheme-1).

\section{CONCLUSION}

The native extract of the various parts of the folk plant $M$. longifolia has been studied for various bio-efficacies. However, it lacks phytochemical screening and characterization of bioactive principles. The present communication for the first time reports its unexplored anti-melanoma bio-efficacy of native bark extract, extracted total flavonoid (possible bioactive principle characterized using HPLCESI-QTOF-MS), and flavonoid loaded gold nanoparticles (nanoscale perspective) against C57BL/6 mice. The proposed phytofabricated gold nanoparticles with no sign of any specific toxicity toward human lymphocytes cells with enhanced anti-melanoma bioefficacy may be proved superior compared to the reference drug (cyclophosphamide)

\section{ACKNOWLEDGMENTS}

The authors gratefully acknowledge Prof. P. K. Kalra, Director, Dayalbagh Educational Institute and Head, Department of Chemistry, Dayalbagh Educational Institute, Dayalbagh, Agra, for the motivation and providing necessary facilities to carry out the research. The promising anti-melanoma activity of the plant Madhuca longifolia has been found in substantially higher among the plants explored for the same bio-efficacy (Table 4).

\section{AUTHORS' CONTRIBUTIONS}

All authors have contributed toward the results, the analytical experiments, numerical simulations, and contributed to the preparation of this manuscript.

\section{CONFLICTS OF INTEREST}

There are no conflicts of interest.

\section{AUTHORS' FUNDING}

This work was supported by the University Grants Commission, New Delhi, for providing Basic Scientific Research Fellowship to Saurabh Yadav and Mukti Sharma [UGC-BSR; F-25-1/201415(BSR)/07-191/2007].

\section{REFERENCES}

1. Jiang TL, Salmon SE, Liu RM. Activity of camptothecin, harriangtonin, cantharidin and curcumae in the human tumor stem cell assay. Eur J Cancer Clin Oncol 1983;19:263-70.

2. Cragg GM, Schepartz SA, Suffness M, Grever MR. The taxol supply crisis. New policies for handling the large-scale production of novel natural product anticancer and anti-hiv agents. J Nat Prod 1993;56:1657-68.

3. Maryam M, Go R, Yien CY, Nazer M. Vinka alkaloids. Int J Prev Med 2013;4:1231-5.

4. Sznarkowska A, Kostecka A, Meller K, Bielawski KP. Inhibition of cancer antioxidant defence by natural compounds. Oncotarget 2017;8:15996-16.

5. Acharya A, Das I, Chandhok D, Saha T. Redox regulation in cancer a double-edged sword with therapeutic potential. Oxid Med Cell Longev 2010;3:23-34

6. Kumari A, Kumar V, Yadav SK. Nanotechnology: A tool to enhance therapeutic values of natural plant products. Trends Med Res 2012;7:34-42.

7. Khan T, Gurav P. Phytonanotechnology: Enhancing delivery of plant based anti-cancer drugs. Front Pharmacol 2018;8:1-14.

8. Silva CO, Pinho JO, Lop JM. Review current trends in cancer nanotheranostics: Metallic, polymeric, and lipid-based systems. Pharmaceutics 2019;11:1-40.

9. Brown SD, Nativo P, Smith JA, Stirling D, Edwards PR, Venugopal B, et al. Gold nanoparticles for the improved anticancer drug delivery of the active component of oxaliplatin. J Am Chem Soc 2010;132:4678-84.

10. Cabuzu D, Ciraj A, Puiu R, Grumezescu AM. Biomedical applications of gold nanoparticles. Curr Top Med Chem 2015;15:1605-13.

11. Venkatachalam P, Sangeetha P, Geetha N, Sahi SV. Phyto-fabrication of bioactive molecules encapsulated metallic silver nanoparticles from Cucumis sativus L. and its enhanced wound healing potential in rat model. J Nanomater 2015;2015:1-9.

12. Ahmed S, Ahmad M, Swami BL, Ikram SA. Review on plants extract mediated synthesis of silver nanoparticles for antimicrobial applications: A green expertise. J Adv Res 2016;7:17-28.

13. Chung IM, Park I, Seung-Hyun K, Thiruvengadam M, Rajakumar G. Plant-mediated synthesis of silver nanoparticles: Their characteristic properties and therapeutic applications. Nanoscale Res Lett 2016;11:1-14.

14. Gholipourmalekabai M, Mobaraki M, Ghaffari M, Zarebkohan A, Omrani VF, Urbanska AM, et al. Targeted drug delivery based on gold nanoparticles derivatives. Curr Pharm Des 2017;23:2918-29.

15. Vijayaraghavan K, Ashokkumar T. Plant-mediated biosynthesis of metallic nanoparticles: A review of literature, factors affecting synthesis, characterization techniques and applications. J Environ Chem Eng 2017;5:4866-83.

16. Du Y, Long X, Ami J, Richey MD, Philippe B, Marion FE, et al. Synthesis and evaluation of doxorubicin-loaded gold nanoparticles for tumor-targeted drug delivery. Bioconjug Chem 2018;29:420-30.

17. Ebrahiminezhad A, Zare-Hoseinabadi A, Sarmah AK, Taghizadeh S, Ghasemi Y, Berenjian A. Plant mediated synthesis and applications of iron nanoparticles. Mol Biotechnol 2018;60:154-68.

18. Burlacu E, Tanase C, Coman NA, Berta L. A review of barkextract-mediated green synthesis of metallic nanoparticles and their applications. Molecules 2019;24:1-18.

19. Ahmad S, Munir S, Zeb N, Ullah A, Khan B, Ali J, et al. Green nanotechnology: A review on green synthesis of silver nanoparticles-an 
eco-friendly approach. Int J Nanomedicine 2019;14:5087-107.

20. Lee KX, Shameli K, Teow SY, Jahangirian H, Moghaddam RR, Webster TJ. Recent developments in the facile bio-synthesis of gold nanoparticles (AuNPs) and their biomedical applications. Int $\mathbf{J}$ Nanomedicine 2020;15:275-300.

21. Kumar A, Thakur RC, Raja W. Mustard oil assisted green synthesis of nanomagnetites. J Mater Environ Sci 2015;6:1105-10.

22. Kittiwisut S, Kraisit P. Physicochemical characterization of propranolloaded chitosan nanoparticles for a buccal drug delivery system. Int J App Pharm 2020;12:243-7.

23. Yadav P, Singh D, Mallik A, Nayak S. Madhuca longifolia (Sapotaceae): A review of its traditional uses, phytochemistry and pharmacology. Int J Biomed Res 2012;3:291-305.

24. Akshatha KN, Murthy MS, Lakshmidevi N. Ethanomedical uses of Madhuca longifolia-A review. Int J Life Sci Pharm Res 2013;3:44-53.

25. Indus S, Annika D. Cytotoxic and antioxidant potential of Madhuca indica flowers. World J Pharm Pharm Sci 2013;5:389-91.

26. Patel PK, Prajapati NK, Dubey BK. Madhuca indica: A review of its medicinal property. Int J Pharma Sci Res 2012;3:1285-93.

27. Ramadan MF, Mohdaly AA, Assiri AM, Tadros M, Niemeyer B. Functional characteristics, nutritional value and industrial applications of Madhuca longifolia seeds: An overview. J Food Sci Technol 2016:53:2149-57.

28. Jerine PS, Prince SE. Diclofenac-induced renal toxicity in female Wistar albino rats is protected by the pre-treatment of aqueous leaves extract of Madhuca longifolia through suppression of inflammation, oxidative stress, and cytokine formation. Biomed Pharmacother 2018;98:45-51.

29. Thirulalaisamy R, Vaijayanthimala M, Govingaraju S, Subramanian A. Phytochemical screening and GC-MS analysis of Madhuca longifolia (L) Macbr. Int J Adv Sci Eng 2015;2:88-93.

30. Annalakshmi R, Mahalakshmi S, Charles A, Sahayam CS. GC-MS and HPTLC analysis of leaf extract of Madhuca longifolia (Koenig) Linn. Drug Invent Today 2013;5:76-80.

31. Inganakal TS, Udupi RH, Swamy P. A new triterpene from Madhuca longifolia L. leaves. Int J Bio Pharma Res 2012;3:718-21.

32. Medhe S, Bansal P, Roy SK, Rajan MG, Srivastava MM. Combination and nanotech enhancement in anti-breast cancer efficacy: Dietary chemo preventing agent. Bionanoscience 2013;3:295-301.

33. Medhe S, Bansal P, Srivastava MM. Enhanced antioxidant activity of gold nanoparticles embedded 3, 6-dihydroxyflavone: A combinational study. Appl Nanosci 2014;4:153-61.

34. Sharma M, Yadav S, Srivastava MM, Ganesh N, Srivastava S. Promising anti-inflammatory bio-efficacy of saponin loaded silver nanoparticles prepared from the plant Madhuca longifolia. Asian J Nanosci Mater 2018;1:244-61.

35. Yadav S, Sharma M, Ganesh N, Srivastava S, Srivastava MM. Bioactive principle loaded gold nanoparticles as potent anti-melanoma agent: Green synthesis, characterization and in-vitro bio-efficacy. Asian J Green Chem 2019;3:492-507

36. Yadav S, Sharma M, Ganesh N, Srivastava S, Srivastava MM. Enhanced anti-melanoma bio-efficacy of flavonoid loaded gold nanoparticles prepared from the plant Madhuca longifolia on the mice and human melanoma cell lines. J Appl Chem 2019;8:833-43.

37. Sharma M, Yadav S, Ganesh N, Srivastava MM, Srivastava S. Biofabrication and characterization of flavonoid loaded $\mathrm{Ag}, \mathrm{Au}, \mathrm{Au}-\mathrm{Ag}$ bimetallic nanoparticles using seed extract of the plant Madhuca longifolia for the enhancement in wound healing bio-efficacy. Prog Biomater 2019;8:51-63.

38. Feleszko W, Mlynarczuk I, Olszewska D, Jalili A, Grzela T, Lasek W, et al. Lovastatin potentiates antitumor activity of doxorubicin in murine melanoma via an apoptosis dependent mechanism. Int J Cancer 2002; $100: 111-8$

39. Corbett T, Valeriote F, Lorusso P, Polin L, Panchapor C, Pugh S. In-vivo methods for screening and preclinical testing. In: Teicher B, editor. Anticancer Drug Development Guide: Preclinical Screening, Clinical Trials and Approval. Totowa, NJ: Humana Press, Inc.; 1998. p. 75-99.

40. Kamal R, Dhawan DK, Chadha VD. Physiological uptake and retention of radio-labelled resveratrol loaded gold nanoparticles (Tc99m-ResAuNp) in colon cancer tissue. Nanomedicine 2018;14:1059-71.

41. Krajian AA. Tissue cutting and staining. In: Frasnkel S, Reitman S, editors. Gradwohl's Clinical Laboratory Methods and Diagnosis. Saint Louis, USA: Mosby Co.; 1963. p. 16-39.

42. Ravishankar D, Rajora AK, Greco F, Osborn HM. Flavonoids as prospective compounds for anti-cancer therapy. Int J Biochem Cell B 2013;45:2821-31.

43. Abotaleb M, Samuel SM, Varghese E, Varghese S, Kubatka P, Liskova A, et al. A review: Flavonoids in cancer and apoptosis. Cancers 2019;11:1-40.

44. Chaudhary A, Bhandari A, Pandurangan A. Antioxidant potential and total phenolic content of methanolic bark extracts of Madhuca indica (Koenig) Gmelin. Anc Sci Life 2012;31:132-36.

45. Gupta VK, Singh R, Sharma B. Phytochemicals mediated signalling pathways and their implications in cancer chemotherapy: Challenges and opportunities in phytochemicals based drug development: A Review. Biochem Compounds 2017;5:1-15.

46. Oboh G, Akomolafe TL, Adetuyi AO. Inhibition of cyclophosphamideinduced oxidative stress in brain by dietary inclusion of red dye extracts from sorghum (Sorghum bicolor) stem. J Med Food 2010;13:1075-80.

47. Bleicher RJ, Ruth K, Sigurdson ER, Beck JR, Ross E, Wong YN, et al. Time to surgery and breast cancer survival in the united states. JAMA Oncol 2016;2:330-9.

48. Liu J, Guo W, Xu B, Ran F, Chu M, Fu H, et al. Angiogenesis inhibition and cell cycle arrest induced by treatment with pseudolarix acid $\mathrm{b}$ alone or combined with 5-fluorouracil. Acta Biochim Biophys Sin 2012;44:490-502.

49. Debnath S, Mukherjee A, Karan S, Debnath M, Chatterjee TK. Induction of apoptosis, anti-proliferation, tumor-angiogenic suppression and down-regulation of dalton's ascitic lymphoma (dal) induced tumorigenesis by poly-l-lysine: A mechanistic study. Biomed Pharmacother 2018;102:1064-76

50. Thummar VR, Parasuraman S, Basu D, Raveendran R. Evaluation of in-vivo antitumor activity of cleistanthin B in swiss albino mice. J Tradit Med Complement Ther 2015;6:383-8.

51. Bryer E, Henary D. Chemotherapy-induced anaemia: Etiology, pathophysiology, and implications for contemporary practice. Int J Clin Transfus Med 2018;6:21-31

52. Shaul ME, Fridlender ZG. Cancer-related circulating and tumorassociated neutrophils-subtypes, sources and function. FEBS J 2018;285:4316-42

53. Lima SR, Veiga VF Jr., Christo HB, Pinto AC, Fernandes PD. In-vivo and in-vitro studies on the anticancer activity of Copaifera multijuga hayne and its fractions. Phytother Res 2003;17:1048-53.

54. Mustapha N, Bzeouich IM, Ghedira K, Hennebelle T, Ghedira LC. Compounds isolated from the aerial part of Crataegus azarolus inhibit growth of B16F10 melanoma cells and exert a potent inhibition of the melanin synthesis. Biomed Pharmacother 2015;69:139-44.

55. Purushotham G, PadmaY, Nabiha Y, Venkata RR. In-vitro evaluation of anti-proliferative, anti-inflammatory and pro-apoptotic activities of the methanolic extracts of Andrographis nallamalayana Ellis on A375 and B16F10 melanoma cell lines.3 Biotech 2016;212:1-11.

56. Spera KD, Figueiredo PA, Santos PC, Barbosa FC, Alves CP, Dokkedal AN, et al. Genotoxicity, anti-melanoma and antioxidant activities of Hymenaea courbaril L. seed extract. An Acad Bras Cienc 2019;91:1-10.

57. Jin S, Kim KC, Kim JS, Jang K, Hyun TK. Anti-melanoma activities and phytochemical compositions of Sorbus commixta fruit extracts. Plants 2020;9:1-9. 